\title{
Knowledge and practice for pressure injury prevention among care managers in a home care setting: a cross-sectional study
}

This article was published in the following Dove Press journal:

Chronic Wound Care Management and Research

9 August 2017

Number of times this article has been viewed

\author{
Masushi Kohta' \\ Yuki Kameda ${ }^{2}$ \\ Sadako Morita ${ }^{3}$ \\ 'Medical Engineering Laboratory, \\ Alcare Co. Ltd., Sumida-ku, Tokyo, \\ Japan; ${ }^{2}$ Wound and Ostomy Care \\ Division, Alcare Co. Ltd., Sumida-ku, \\ Tokyo, Japan; ${ }^{3}$ Sumire Home-visit \\ Nursing Station, Handa-city, Aichi, \\ Japan
}

Purpose: Previous studies on pressure injury prevention using questionnaire surveys have targeted physicians and nurses working in hospitals. However, few have administered surveys to social welfare professionals at home care. Thus, this study aimed to investigate the current level of knowledge and practice regarding pressure injury prevention among Japanese care managers. Patients and methods: A cross-sectional study among care managers working in a Japanese city was performed from June to July 2016. Data were collected using a questionnaire to assess the participants' knowledge of and practice for pressure injury prevention. The questionnaire included 1) measures of demographic characterization, 2) measures of knowledge, 3) measures of practice, and 4) measures of the difficulties of using pressure injury risk assessment scales. Results: A total of 48 participants were analyzed (response rate: $55 \%$ ). The overall knowledge and practice scores were $78.6 \%$ and $61.8 \%$, respectively. The percentages of participants who knew the risk assessment scales were $38 \%, 26 \%$, and $13 \%$ for the Braden scale, the Ohura-Hotta scale, and the University of Kanazawa scale, respectively. We also observed that $50 \%$ of the participants in this study believed that the use of risk assessment scales in daily practice in home care may be difficult. Conclusion: Through the results of this questionnaire survey, we concluded that the current levels of knowledge and practice regarding pressure injury prevention among the care managers participating in our study were "moderate" and "low", respectively. Low scores were obtained for knowledge with respect to the question, "Using risk assessment scales". We will develop a new risk assessment scale as a bridge between both medical professionals and social welfare professionals. Practically, the authors recommend care managers should receive continuous education and practical training for pressure injury prevention in a home care setting.

Keywords: long term care, Braden scale, questionnaire, risk assessment, pressure ulcer

\section{Introduction}

We face a worldwide increase of aging population, chronic diseases, and financial crisis of the social security payment. In this situation, the Japanese government has strongly promoted home health care for the purpose of minimizing an increase in medical costs due to a prolonged hospital stay. ${ }^{1}$ The number of individuals who needed long-term care at Japanese home under Japan-specific long-term care insurance system was determined to be 5.8 million in 2015; this was approximately three times higher than it was when the system was implemented in 2000., ${ }^{2,3}$ Most of the individuals have specific medical conditions that are associated with pressure injury development; ${ }^{4}$ consequently, the number of individuals at risk of developing pressure injuries at home in Japan appears to be increasing. Reportedly, this incidence rate was $13 \%,{ }^{5}$ which was higher than that in patients admitted to university and general hospitals. ${ }^{6}$
Correspondence: Masushi Kohta

I-2I-I0 Kyojima, Sumida-ku, Tokyo

131-0046, Japan

Tel +81336111101

Fax +81336136894

Email mkouta@alcare.co.jp 
In 2016, a change in terminology from pressure ulcer to pressure injury was announced and the definition of a pressure injury was updated that it is localized damage to the skin and/or underlying soft tissue usually over a bony prominence or related to a medical or other device, as a result of intense and/or prolonged pressure or pressure in combination with shear. ${ }^{7}$ The development of pressure injuries has several negative effects in home care patients, including increased pain, risk of infection at the wound site, medical costs for pressure injury treatment, and subsequent decline in quality of life for the individual and their families. ${ }^{89}$ Thus, professional intervention for the individuals who are at risk for pressure injuries at home is a key factor in the successful prevention or early detection of pressure injuries.

Home care should help people to be independent as long as possible and to avoid unnecessary nursing home and hospital admissions. Appropriate collaborations among various types of professionals such as medical professionals and social welfare professionals are essential to provide quality pressure injury management during home care. ${ }^{10}$ Hence, it is important for such professionals to maintain current knowledge and practice for pressure injury management. In the USA and some European countries, questionnaire surveys on the knowledge and practices regarding pressure injury prevention have been performed for physicians, nurses, and nursing students in acute care settings. ${ }^{11-14}$ Similar reports from Japan have been published. ${ }^{15,16}$ In the home care setting, Fujita et al recently evaluated a questionnaire survey on pressure injury prevention among caregivers at home care and clarified that the levels of knowledge and practice among them were relatively low. ${ }^{17}$

Based on the findings noted above, previous studies on questionnaire surveys about pressure injury prevention have mainly targeted medical professionals such as physicians and nurses who worked for hospitals. However, few have investigated the knowledge and practice among social welfare professionals. In this study, we focused only on a Japanese social welfare professional called a "care manager" who receives the certificate of care manager for possessing specialized knowledge and techniques to provide assistance necessary for individuals in need of nursing care to live independent lives. ${ }^{18}$ Care manager is an official qualification in Japanese social and welfare system. Experts engaged in clinical practice based on a national or official license for 5 years or more can take an examination to obtain the official license called "care manager". This national or official license is available to home care physicians, home-visiting nurses, care workers, social workers and psychiatric social workers.
To be a care manager, it is required to pass the examination, to receive a brief training, and to obtain a social welfare license called "care manager". This role has been introduced under the long-term care insurance system at home care in Japan. Under the insurance system, the care manager has to provide care management services including confirmation of conditions of individuals, developing and managing an individual care service plan, assistance for fulfilling the procedure for using the service, and managing the implementation situation of the care service plan. ${ }^{19}$ In addition, the care service plan should be adjusted based on changes to each individual situation. ${ }^{20}$ To check the current physical and mental condition of individuals, the care manager visits the house of each individual to interview them at least once a month. Thus, the care manager is a key person for successfully providing perspectives on necessary support for individuals who receive long-term care under the long-term care insurance system and forming collaboration between medical and social welfare services.

The aim of this study was to investigate the current levels of knowledge and practice on pressure injury prevention among care managers in Japan.

\section{Patients and methods Study design}

We conducted a cross-sectional study that included care managers who worked for home care support facilities in Handa city, Aichi, Japan. The questionnaire survey was conducted from June 2016 to July 2016.

\section{Setting and sample}

The target institutions were the 27 facilities that were listed as of June 2016 in the Handa Care Managers Study Group (HKB75). All of the facilities in which the care managers work in Handa city participate in the HKB75; therefore, eligible samples included in this study were all care managers who worked for the facilities in Handa city. The HKB75 is held regularly for information exchange and acquisition of knowledge. The authors orally explained the outline of this study to the members of the executive committee of the HKB75 and received written agreement for cooperation with this study. Each care manager in Handa city was given a request sheet which included detailed information about the study objectives. Study participation was voluntary and anonymous; therefore, the return of the questionnaire was considered to be consent.

This study was approved by Ethics Committee of Aichi Nursing Association within which the work was undertaken and it conforms to the provisions of the Declaration of Helsinki. 


\section{Questionnaire}

A draft of the questionnaire was developed in consultation with previous reports ${ }^{17}$ and the diagnosis and treatment guidelines that were provided by the Japanese Society of Pressure Ulcers. ${ }^{21}$ The authors received some advice from an associate professor who specialized in home care nursing, and the questionnaire used in this study was finally prepared. Before the actual data collection, the questionnaire was pretested with three care managers. The questionnaire took an average of 20 minutes to complete.

The questionnaire included 46 measures which were divided into four parts. The first part covered the demographic characteristics, which included age, gender, level of education, years since earning a care manager license, years of continuous employment at the current facility, professional background, facility type, and caseload.

In the second part, the participants were evaluated for their knowledge of preventive strategies against pressure injuries. This part consisted of 22 questions reflecting six sections: 1) reduction of pressure, 2) reduction of shearing forces or frictions, 3) dry/wet management of skin, 4) nutrition, 5) risk assessment scale, and 6) measures that were not useful in pressure injury prevention. The correct answer for these preventive strategies was shown in the 22 questions. The questionnaire in this section asked whether the participants knew the strategy or not. The participants answered the questions about their knowledge of pressure injury prevention by selecting between "know" or "do not know". A score of "1" was given for participants who selected "know," and a " 0 " was given for those who answered "do not know". The maximum knowledge score value was 22 for each participant in this section.

In the third part, the participants were asked about the practice of preventive strategies for pressure injuries. This part consisted of six questions reflecting three sections: 1) establishment of a care plan, 2) prevention of pressure injury development, and 3) prevention of pressure injury deterioration. The correct answer for preventive pressure injury strategies was shown in the six questions. The questionnaire in this section asked whether the participants implemented those actions or not. The answer choice for each question was "practice" or "do not practice". A score of "1" was given when the participants answered "practice", and a " 0 " was given for those who answered "do not practice". The maximum practice score value was six for each participant in this section.

The final part of this questionnaire assessed the difficulty of using pressure injury risk assessment scales, such as the
Braden scale, the Ohura-Hotta $(\mathrm{OH})$ scale, and the University of Kanazawa (K) scale. These Japanese language scales have been published and are well-known pressure injury risk assessment scales for physicians and nurses in Japanese hospitals. ${ }^{5,22}$ The scales were described in the questionnaire, and the participants checked the scales before answering the questions. In this section, participants were asked whether using the risk assessment scale in daily clinical practice was easy or not. The answer options were "easy", "not easy", and "did not know". For each question, participants who answered "easy" were categorized as the "easy" group and the remaining participants were listed in the "not easy" group.

\section{Data collection}

The requisite number of questionnaires and return envelopes were sent in an envelope to each facility. The completed questionnaires had to be returned within a 3-week period, and the questionnaire was placed in an envelope and anonymously returned to the authors by each care manager.

\section{Data analysis}

The continuous variables were expressed as mean values and ranges, and the categorical variables were expressed as numbers and percentages. The level of knowledge for the participants in this study was determined according to the previous reports in which the learning outcome criteria for pressure injury prevention were described; the word "very low" represented a mean knowledge score of $<60 \%$, the word "low" represented a mean knowledge score between $60 \%$ and $60.99 \%$, the word "moderate" represented a mean knowledge score between $70 \%$ and $70.99 \%$, the word "high" represented a mean knowledge score between $80 \%$ and $89.99 \%$, and the word "very high" represented a mean knowledge score between $90 \%$ and $100 \% .{ }^{23} \mathrm{~A}$ similar analysis was performed in evaluating the level of practice. All data analyses were conducted using SPSS version 20.0 software (IBM Corporation, Tokyo, Japan). The missing values were excluded from our data analyses.

\section{Results \\ Participant's characteristics}

A total of 48 out of 87 participants were analyzed (response rate: $55 \%$ ). The demographic characteristics of the care managers in this study are shown in Table 1 . The majority of participants who enrolled in this study were 50-59 years old $(48 \%)$ and female (90\%). Majority of the participants were care workers $(51 \%)$ and nurses $(22 \%)$. The mean caseload size for each participant was 30.6 patients (range: 4-50). 
Table I Participant demographic characteristics

\begin{tabular}{|c|c|c|}
\hline Characteristics & Overall $^{a}$ & $\begin{array}{l}\text { Missing } \\
\text { values }\end{array}$ \\
\hline Age in years, $n(\%)$ & & 0 \\
\hline $30-39$ & $5(10)$ & \\
\hline $40-49$ & II (23) & \\
\hline $50-59$ & $23(48)$ & \\
\hline $60-69$ & $9(19)$ & \\
\hline Gender, n (\%) & & 0 \\
\hline Male & $5(10)$ & \\
\hline Female & $43(90)$ & \\
\hline Level of education, $n$ (\%) & & 2 \\
\hline Senior high school & $15(33)$ & \\
\hline Vocational college & II (24) & \\
\hline National Institute of Technology & $3(7)$ & \\
\hline Junior college & $6(13)$ & \\
\hline University & $9(20)$ & \\
\hline Graduate school of university & $2(4)$ & \\
\hline Years since gaining care manager license, $n(\%)$ & & 1 \\
\hline$<3$ & $7(15)$ & \\
\hline$\geq 3$ and $<5$ & $3(6)$ & \\
\hline$\geq 5$ and $<10$ & $16(34)$ & \\
\hline$\geq 10$ & $21(45)$ & \\
\hline $\begin{array}{l}\text { Years of continuous employment in current } \\
\text { facility, } n(\%)\end{array}$ & & 0 \\
\hline$<3$ & $12(25)$ & \\
\hline$\geq 3$ and $<5$ & $5(10)$ & \\
\hline$\geq 5$ and $<10$ & $17(35)$ & \\
\hline$\geq 10$ & $14(29)$ & \\
\hline Professional background, $\mathrm{n}(\%)^{\mathrm{b}}$ & & 0 \\
\hline Care worker & $28(5 \mathrm{I})$ & \\
\hline Social worker & $8(15)$ & \\
\hline Psychiatric social worker & $3(5)$ & \\
\hline Registered nurse & $12(22)$ & \\
\hline Others & $4(6)$ & \\
\hline Facility type, $n(\%)$ & & 0 \\
\hline In-home long-term care support facility & $46(96)$ & \\
\hline Others & $2(4)$ & \\
\hline Caseload, mean (range) & $30.6(4-50)$ & 1 \\
\hline Support required I-2, mean (range) & $9.3(2-26)$ & 2 \\
\hline Care levels $\mathrm{I}-2$, mean (range) & $16.6(0-30)$ & 2 \\
\hline Care levels 3-5, mean (range) & $6.3(0-16)$ & 2 \\
\hline
\end{tabular}

Notes: aFrom a total of 87 care managers, 48 completed the questionnaire (response rate: 55\%). ${ }^{\text {'The }} 48$ participants come from 55 professional backgrounds.

\section{Knowledge}

The respective questions and the number of participants who answered "know" for pressure injury prevention knowledge are summarized in Table 2. For questions 1, 3, 4, 10, 14, and 15 , all participants answered "know". The mean percentage was $78.6 \%$, and the level of knowledge was determined to be "moderate". Only $47 \%$ of the participants were able to answer question number 13 with "using an anal plug for protecting skin from exposure to excrement contamination". A lower score was obtained for the section "using the risk assessment scale", and the percentages of participants who answered "know" in this section were 38\%, 26\%, and $13 \%$ for the Braden scale, the $\mathrm{OH}$ scale, and the $\mathrm{K}$ scale, respectively.

\section{Practice}

The respective questions and the number of participants who answered "practice" for the pressure injury prevention practice are summarized in Table 3. Among the answer options on the questionnaire, no one achieved a $100 \%$ practice score. The mean percentage was $61.8 \%$, and the level of practice was determined to be "low".

\section{Risk assessment scale}

The difficulties of using risk assessment scales which have already been accepted in Japan were evaluated in this section. Table 4 shows that the mean percentages of participants who answered that the Braden scale, the $\mathrm{OH}$ scale, and the $\mathrm{K}$ scale were "easy" to use were $38 \%, 49 \%$, and $35 \%$, respectively.

\section{Discussion}

It has been emphasized that individuals who receive home care should be able to receive satisfactory care at home or at another non-hospital residence..$^{10}$ However, the evidence on questionnaire surveys covering pressure injury prevention during home care in Japan is limited. ${ }^{17}$ As a first step, this trial described the care manager's current level of knowledge and practice in pressure injury management. The results of this study provide a foundation for the development of interventions to increase the use of correct preventive strategies in daily practice for Japanese home care.

Less than half of the participants answered "know" for question number 13 in this study. This trend was also shown in a previous report. ${ }^{17}$ The anus bag technique has never been popular in the home care setting, whereas it has sometimes been used for bedridden patients in hospitals in Japan. Thus, we determined that it should not be included in the questionnaire for professionals working in the home care setting.

The mean percentage of participants who answered "know" for the section "Using the risk assessment scale" was relatively low. The use of a risk assessment scale has been widely known to be recommended for predicting pressure injury development in the acute care setting. ${ }^{24}$ Recently, a researcher, who was an administrator of a Home Nursing Department in a home-visit nursing agency in Japan, reported that the Braden scale was useful in a group discussion where different specialists and family members were present for home care. ${ }^{25}$ Additionally, Japan-specific pressure injury risk assessment scales, the $\mathrm{OH}$ scale and $\mathrm{K}$ scale, have been developed to evaluate pressure injury risk in elderly 
Table 2 Knowledge on pressure injury prevention among the participants

\begin{tabular}{|c|c|c|c|}
\hline \multicolumn{2}{|c|}{ Questionnaire } & n (\%) ${ }^{a}$ & Missing data \\
\hline \multicolumn{4}{|c|}{ Reducing the pressure } \\
\hline I & Repositioning individuals at least every 2 hours & $47(100)$ & 1 \\
\hline 2 & Using the $30^{\circ}$ tilted side-lying position, if tolerable to individuals & $39(83)$ & 1 \\
\hline 3 & Using a pressure redistribution mattress & $47(100)$ & 1 \\
\hline 4 & Using an adequate wheelchair that is acceptable to the individuals & $47(100)$ & 1 \\
\hline \multicolumn{4}{|c|}{ Reducing shearing force or friction } \\
\hline 5 & $\begin{array}{l}\text { Individuals who can move should consider repositioning at least every } 2 \text { hours when they are seated in a } \\
\text { chair or on the floor }\end{array}$ & $46(96)$ & 0 \\
\hline 6 & Applying prophylactic dressing to the skin site that is at a high risk of pressure injury development & $38(79)$ & 0 \\
\hline 7 & Do not massage the area that you receive pressure on & $42(88)$ & 0 \\
\hline 8 & Limit head-of-bed elevation to $30^{\circ}$ for individuals on bedrest & $33(69)$ & 0 \\
\hline \multicolumn{4}{|c|}{ Dry/wet management of the skin surface } \\
\hline 9 & Consider wiping the individual's skin sites by using a towel, without rubbing the skin & $34(7 \mathrm{I})$ & 0 \\
\hline 10 & Using high-absorbency diapers & $48(100)$ & 0 \\
\hline 11 & Regularly changing the individual's diaper & $47(98)$ & 0 \\
\hline 12 & Protect the skin from exposure to excessive moisture with a water-repellent barrier cream, as in diarrhea & $40(83)$ & 0 \\
\hline 13 & Consider using an anus bag for protecting the skin from exposure to excrement contamination & $21(44)$ & 0 \\
\hline \multicolumn{4}{|c|}{ Nutrition } \\
\hline 14 & Consider eating between meals when nutritional requirements cannot be achieved through dietary intake & $47(100)$ & I \\
\hline 15 & Provide additional nutritional supplements (e.g., ENSURE LIQUID, RACOL) in addition to the usual diet & $47(100)$ & I \\
\hline 16 & Provide adequate protein in usual diet & $39(83)$ & I \\
\hline 17 & Provide/encourage an individual to take their favorite food when dietary intake is poor & $47(98)$ & 0 \\
\hline \multicolumn{4}{|c|}{ Risk assessment scale } \\
\hline 18 & Using the Braden scale & $18(38)$ & I \\
\hline 19 & Using the $\mathrm{OH}$ scale & $12(26)$ & I \\
\hline 20 & Using the $\mathrm{K}$ scale & $6(13)$ & 1 \\
\hline \multicolumn{4}{|c|}{ Measures that are not useful in pressure injury prevention } \\
\hline 21 & Do not consider using an aseptic technique when the individual is not immunocompromised & $40(83)$ & 0 \\
\hline 22 & Do not dry the pressure injury & $38(79)$ & 0 \\
\hline \multicolumn{2}{|c|}{ Composite percentage of scores } & 78.6 & \\
\hline \multicolumn{2}{|c|}{ Level of knowledge } & Moderate & \\
\hline
\end{tabular}

Note: an (\%) indicates the number and percentage of participants who answered "know" in each measure.

Abbreviations: K, University of Kanazawa; $\mathrm{OH}$, Ohura-Hotta.

Table 3 Practice of pressure injury prevention among the participants

\begin{tabular}{lll}
\hline Questionnaire & n (\%) & Missing data \\
\hline Planning & $34(72)$ & $32(68)$ \\
I Developing an individualized care plan for individuals with or at risk of a pressure injury & & 1 \\
$2 \quad$ Revising an individualized care plan by considering the individual's condition & $13(28)$ \\
Prevention of developing pressure injury & $33(72)$ \\
$3 \quad$ Taking counsel with a physician for individuals at risk of a pressure injury & 2 \\
$4 \quad$ Taking counsel with a nurse for individuals at risk of a pressure injury & $25(56)$ \\
Prevention of pressure injury deterioration & $34(76)$ & 2 \\
$5 \quad$ Taking counsel with a physician for individuals at risk of a pressure injury deterioration & 3 \\
$6 \quad$ Taking counsel with a nurse for individuals at risk of a pressure injury deterioration & 3 \\
Composite percentage of scores & Low \\
Level of knowledge &
\end{tabular}

Note: ${ }^{2} \mathrm{n}(\%)$ indicates the number and percentage of participants who answered "practice" in each measure.

Japanese individuals. ${ }^{5,22}$ However, our result in this section indicated that these risk assessment scales might not become widespread in the field of home care where Japanese social welfare professionals work. The participants in this study were only care managers; however, their background varied from person to person (e.g., medical professional or social welfare professional or both). We consider that the knowledge level of the pressure injury assessment scale could be low in this study because our participants other than the participants who had a license of nursing might not have received sufficient training and education about the assessment scales. Education on the prevention and treatment of pressure injury 
Table 4 Difficulty of using a risk assessment scale

\begin{tabular}{lll}
\hline Risk assessment scale & $\mathbf{n}(\%)^{\mathbf{a}}$ & Missing data \\
\hline Braden scale & $15(38)$ & 7 \\
OH scale & $18(49)$ & 9 \\
K scale & $13(35)$ & 9 \\
\hline
\end{tabular}

Note: ${ }^{a} \mathrm{n}(\%)$ indicates the number and percentage of participants who were categorized into the group "easy" in this study.

Abbreviations: $\mathrm{K}$, University of Kanazawa; $\mathrm{OH}$, Ohura-Hotta.

can have a positive effect in regard to raising the knowledge level of chronic diseases at a home care setting. One previous report showed that a case study meeting was held to share knowledge and the standard of pressure injury assessment at a Japanese home-visiting nursing station. ${ }^{25}$

The level of practice for participants in this study was determined to be "low" (Table 3). Our results suggested that the participants in this study rarely communicated with physicians about the patient's condition to prevent pressure injury development. The role of the care manager is to act as an intermediary between the medical professionals and social welfare professionals. However, it is difficult for care managers to consult with physicians and nurses before the development of pressure injuries at Japanese homes. Most care managers also believe that intervention by medical professionals does not start until after pressure injury development. ${ }^{26}$ Therefore, to resolve this problem, we suggest that care managers and medical professionals should form an informational network using common knowledge or standards (e.g., risk assessment scales).

Our results demonstrated that risk assessment scales which have already been established by previous researchers may be difficult to use during daily practice among care managers (Table 4). The reasons are not clear, but the proportion of participants who were categorized into the "easy" group in section 4 was $<50 \%$ in this study. Only one previous clinical study using the Braden Scale to predict pressure injury development at home care has been reported, ${ }^{27}$ but the high-level evidence of scale efficacy has not been established. Additionally, Bergquist-Beringer and Daley argued that the current guidelines for pressure injury prevention could be incompatible with home care because the guidelines were based on care algorithms that were produced by clinical cases in acute care settings. ${ }^{28}$ Current risk assessment scales may be understood by professionals other than medical and nursing stuffs in acute care setting. However, the authors, as researchers or practitioners at home health care, consider that the busy schedule made it difficult for social welfare professions including Japanese care managers to acquire the knowledge and practice and correctly use them in their daily work. ${ }^{29}$ In addition, there are different perspectives between acute care and social welfare professionals in regard to the assistance for individuals who needed long-term care at home. Therefore, more simply, new risk assessment scale that is compatible with the viewpoint of home care is required. This scale can be expected to develop an interest in the prevention of pressure injury and improvement of the level of education. We will develop a new risk assessment scale as a bridge between both medical professionals and social welfare professionals in Japanese home care nursing in the near future.

The participants regularly held a case study meeting or session in their community and had the opportunity to share information through the meeting at home care. As a practical recommendation, the authors think that continuous education and practical training in their area through their efforts, including holding a case study meeting, will support to advance knowledge and to be a collaborative activity by evidence-based care in the prevention of pressure injury development.

\section{Limitation}

A limitation of this study was the small number of participants. It focused on care managers working in the area of Handa city, which limits the generalizability to other care managers in home care.

\section{Conclusion}

In this questionnaire survey, we concluded that the current level of knowledge and practice regarding pressure injury prevention among care managers was "moderate" and "low", respectively. Low scores were obtained for knowledge with respect to the question "Using risk assessment scales". Of the participants in this study, 50\% thought that the use of risk assessment scales in daily practice in home care may be difficult.

\section{Acknowledgments}

We would like to thank Associate Professor Y Sasaki (Aichi Medical University) for her helpful advice on preparing the questionnaire in this study. We would also like to thank Enago for its English language review. This project was supported by an unrestricted fund from ALCARE.

\section{Author contributions}

All authors substantially participated in the conception, study design, data acquisition, and data analysis. All authors also contributed to drafting the manuscript and critical revisions 
for important intellectual content, and gave their final approval for the version to be published. Finally, all authors agreed to be accountable for all aspects of this work to ensure that questions related to the accuracy or integrity of any part of this work would be appropriately investigated and resolved.

\section{Disclosure}

MK and YK are employees of ALCARE Co, Ltd (Tokyo, Japan). The other authors report no conflicts of interest in this work.

\section{References}

1. Nagasawa S. Long-term care insurance act and home care. Japan Med Assoc J. 2015;58(1-2):23-26.

2. Takada M, Nakano S, Mitamura S, et al. [A research survey of interprofessional collaboration about the pharmaceutical service by pharmacies and visiting nurse stations]. Jpn J Soc Pharm. 2015;34(2):116-127. Japanese.

3. Fukutomi E, Kimura Y, Wada T, Okumiya K, Matsubayashi K. Longterm care prevention project in Japan. Lancet. 2013;381(9861):116.

4. Margolis DJ, Knauss J, Bilker W, Baumgarten M. Medical conditions as risk factors for pressure ulcers in an outpatients setting. Age Ageing. 2003;32(3):259-264.

5. Murayama S, Kitayama Y, Okuwa M, et al. [Development of a pressure ulcer risk assessment scale for the home-care setting]. Jpn JPU. 2007;9(1):28-37. Japanese.

6. Sanada H, Miyachi Y, Ohura T, et al. The Japanese pressure ulcer surveillance study: a retrospective cohort study to determine the prevalence of pressure ulcers in Japanese hospitals. Wounds. 2008;20(6): 176-182.

7. Salcido R. From pressure ulcers to "pressure injury": disambiguation and anthropology. Adv Skin Wound Care. 2016;29(7):295.

8. Bennett G, Dealey C, Posnett J. The cost of pressure ulcers in the UK. Age Ageing. 2004;33(3):230-235.

9. Tsukada K. [Pressure ulcer classification and standard healing period]. Jpn J PU. 2006;8(1):12-20. Japanese.

10. Yamamoto-Mitani, Igarashi A, Noguchi-Watanabe M, Takemura Y, Suzuki M. Factors of good collaboration in home-based end-of-life care: a questionnaire survey of Japanese home care nurses, home helpers, and care managers. Care Manage J. 2015;16(3):129-140.

11. Levine JM, Ayello EA, Zulkowski KM, Fogel J. Pressure ulcer knowledge in medical residents: an opportunity for improvement. Adv Skin Wound Care. 2012;25(3):115-117.

12. Meesterberends E, Wilborn D, Lohrmann C, Schols JM, Halfens RJ. Knowledge and use of pressure ulcer preventive measures in nursing homes: a comparison of Dutch and German nursing stuff. $J$ Clin Nurs. 2014;23(13-14):1948-1958.
13. Simonetti V, Comparcini D, Flacco ME, Di Giovanni P, Cicolini G. Nursing student's knowledge and attitude on pressure ulcer prevention evidence based guideline: a multicenter cross-sectional study. Nurse Educ Today. 2015;35(4):573-579.

14. Cox J, Roche S, Gandhi N. Critical care physicians: attitudes, beliefs, and knowledge about pressure ulcers. Adv Skin Wound Care. 2013;26(4):168-176.

15. Okamoto Y, Ukai J, Nakane O, Nakanishi Y. [Difference in attitude toward pressure ulcer among the departments of general hospitals - A questionnaire survey of clinicians]. Jpn J PU. 2003;5(1):10-15. Japanese.

16. Sano S, Tanabe S, Nishikawa K. [The survey on knowledge in the pressure ulcer care of nurse]. J Niigata Seiryo Acad Soc. 2010;2(1):31-37. Japanese.

17. Fujita N, Yasuda T, Yoshii S, Douken Y. [Connection between perceived care burden and sense of affirmation in pressure ulcer prevention behavior in family care situations]. J Jpn Soc Nurs Res. 2010;33(2):113-124. Japanese.

18. Yamada M, Hagihara A, Nobutomo K. Family caregivers and care manager support under long-term care insurance in rural Japan. Psychol Health Med. 2009;14(1):73-85.

19. Watanabe M, Yamamoto-Mitani N, Nishigaki M, et al. Care manager's confidence in managing home-based end-of-care: a cross sectional study. BMC Geriatr. 2013;13:67.

20. Murashima S, Nagata S, Magilvy JK, Fukui S, Kayama M. Home care nursing in Japan: a challenge for providing good care at home. Public Health Nurs. 2002;19(2):94-103.

21. The Japanese Society of Pressure Ulcers Revision Committee. [JSPU guidelines for the prevention and management of pressure ulcers (4th Ed)]. Jpn J PU. 2015;17(4):487-557. Japanese.

22. Ohura T. [Risk factors for pressure ulcers of elderly people]. Jpn JPU. 2002;4(3):397-405. Japanese.

23. Uba MN, Alih FI, Kever RT, Lola N. Knowledge, attitude and practice of nurses toward pressure ulcer prevention in university of Maiduguri Teaching Hospital, Borno State, North-Eastern, Nigeria. Int J Nurs Midwifery. 2015;7(4):54-60.

24. Deeks JJ. Pressure sore prevention: using and evaluating risk assessment tools. Br J Nurs. 1996;5(5):313-320.

25. Inoue $T$. The present situation and the problem of visiting nursing: team care management of pressure ulcer in the elderly. Japan Med Assoc J. 2015;58(1-2):19-22.

26. Kashiwagi M, Tamiya N, Murata M. Characteristics of visiting nurse agencies with high home death rates: a prefecture-wide study in Japan. Geriatr Gerontol Int. 2015;15(8):936-943.

27. Lyder CH, Shannon R, Empleo-Frazier O, McGeHee D, White C. A comprehensive program to prevent pressure ulcers in long-term care: exploring costs and outcomes. Ostomy Wound Manage. 2002;48(4):52-62.

28. Bergquist-Beringer S, Daley CM. Adapting pressure ulcer prevention for use in home health care. JWOCN. 2011;38(2):145-154.

29. Kwong EW, Lau AT, Lee RL, Kwan RY. A pressure ulcer prevention programme specially designed for nursing homes: does it work? J Clin Nurs. 2011;20(19-20):2777-2786.
Chronic Wound Care Management and Research

\section{Publish your work in this journal}

Chronic Wound Care Management and Research is an international, peer reviewed, open access, online journal publishing original research, reviews, editorials, and commentaries on the causes and management of chronic wounds and the major issues related to chronic wound management. Topics also include chronic wounds as comorbidities to other

Submit your manuscript here: https://www.dovepress.com/chronic-wound-care-management-and-research-journal

conditions, patient adherence to therapy, and the economic burden of chronic wounds. The manuscript management system is completely online and includes a very quick and fair peer review system, which is all easy to use. Visit http://www.dovepress.com/testimonials.php to read real quotes from published authors. 